\title{
LeWitt, in the Shadow \\ of the Object
}

RYE DAG HOLMBOE

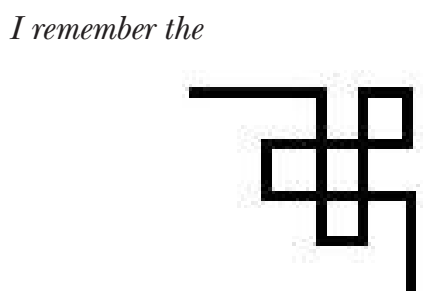

in the metro.

—Georges Perec, I Remember (1978)

In 1976, Sol LeWitt produced a group of wall drawings in the Torre Bonomo, a medieval tower in the Umbrian town of Spoleto, Italy. ${ }^{1}$ At the time, the artist lived with the Bonomo family in a converted sixteenth-century hermitage in the nearby mountains and used the family's tower as a studio. The group comprises an elaborate series of line, shape, and word drawings, three grids in which different combinations of geometric figures are exhausted, and a statement that reads, tautologically, ON THIS WALL ONE FINDS THIS WRITING.

One year later, LeWitt produced a further series of wall drawings for an exhibition in the Torre Bonomo, one of several shows held there between 1976 and 1993. The temporary and site-specific character of the exhibition meant that some of these drawings were soon covered up. A large circle made in black charcoal, which formed part of a series of six geometric shapes drawn directly onto the tower's white plastered walls, is now barely visible beneath a brightly colored abstract painting by the Italian artist Nicola de Maria, while two other drawings from this series, a trapezoid and a parallelogram, were painted over in white so as

1. Many thanks are due to those who made this essay possible. First, a special thanks to the Mahler \& LeWitt Studios for inviting me on residency to research this essay. Special thanks to Guy Robertson, the program's director, for his invaluable comments on various drafts of the essay and for his support during the residency; to Valentina Bonomo for generously allowing me to stay in the tower; and to Joschi Herczeg for the photographs of the drawings. Thanks also to Eva LeWitt, David Gothard, Tom Weaver, Andrew Witt, and Giulia Smith for early comments, to Lindsay Aveilhé, Sofia LeWitt, and the estate of Sol LeWitt for fact-checking the essay, and to Yve-Alain Bois and Mignon Nixon for their useful edits on my final draft. 


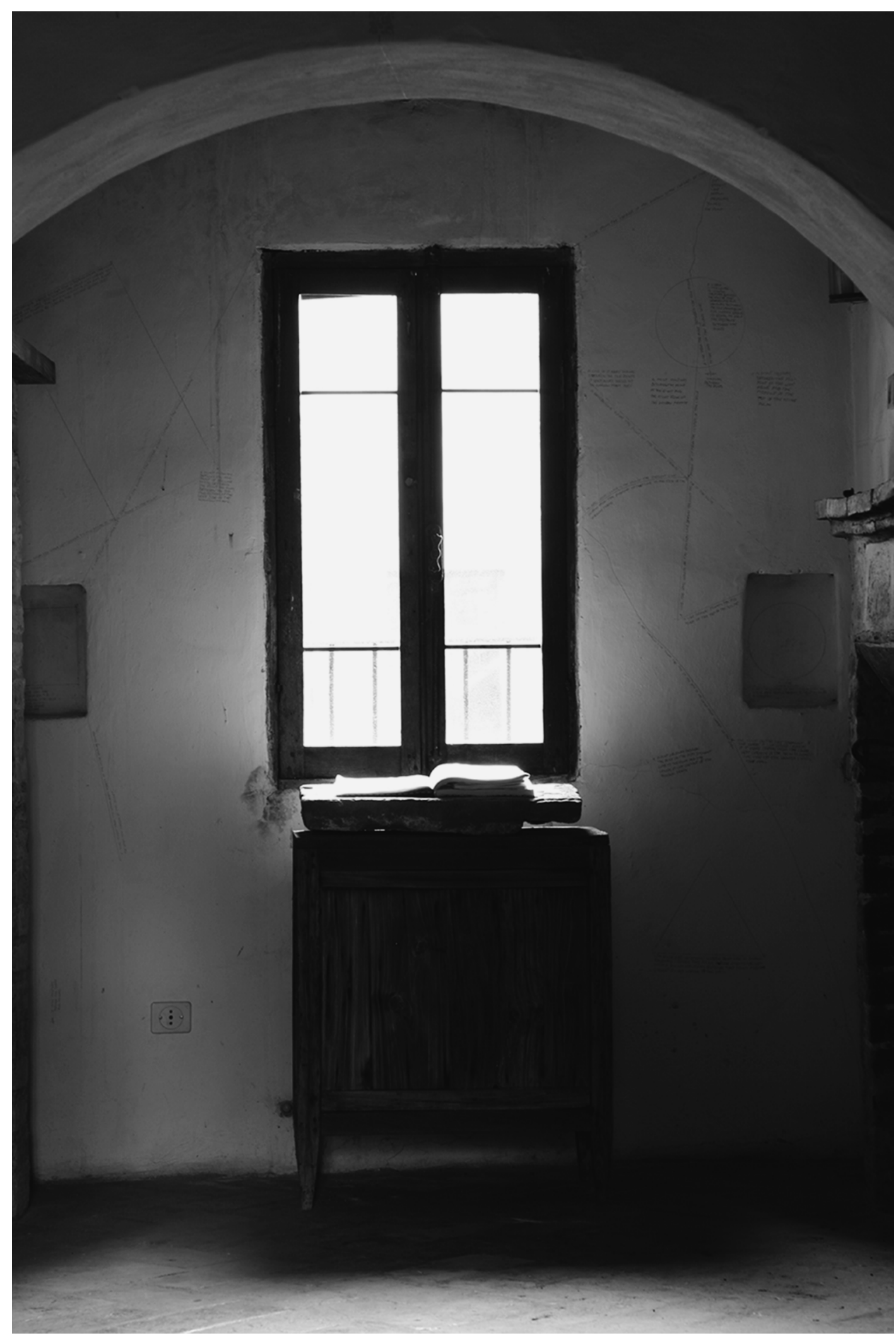

Sol LeWitt. Studio Drawings. 1976. 
not to distract attention from the works of future artists. The pencil drawings made in 1976 are different, and singular in LeWitt's oeuvre, because they were not initially meant for public viewing, so that for some time they were shared only by other artists invited to take up residence in the tower. For this reason, they might better be termed studio drawings, or perhaps "studiowork," the expression used by Briony Fer to describe the objects left behind in Eva Hesse's studio after her death in 1970 , objects that were more provisional and in some ways more difficult to define than her finished work. ${ }^{2}$

What is immediately striking about the studio drawings is the way in which they reveal LeWitt's makeshift, trial-and-error working method. The attempt to exhaust every combination of six geomet-

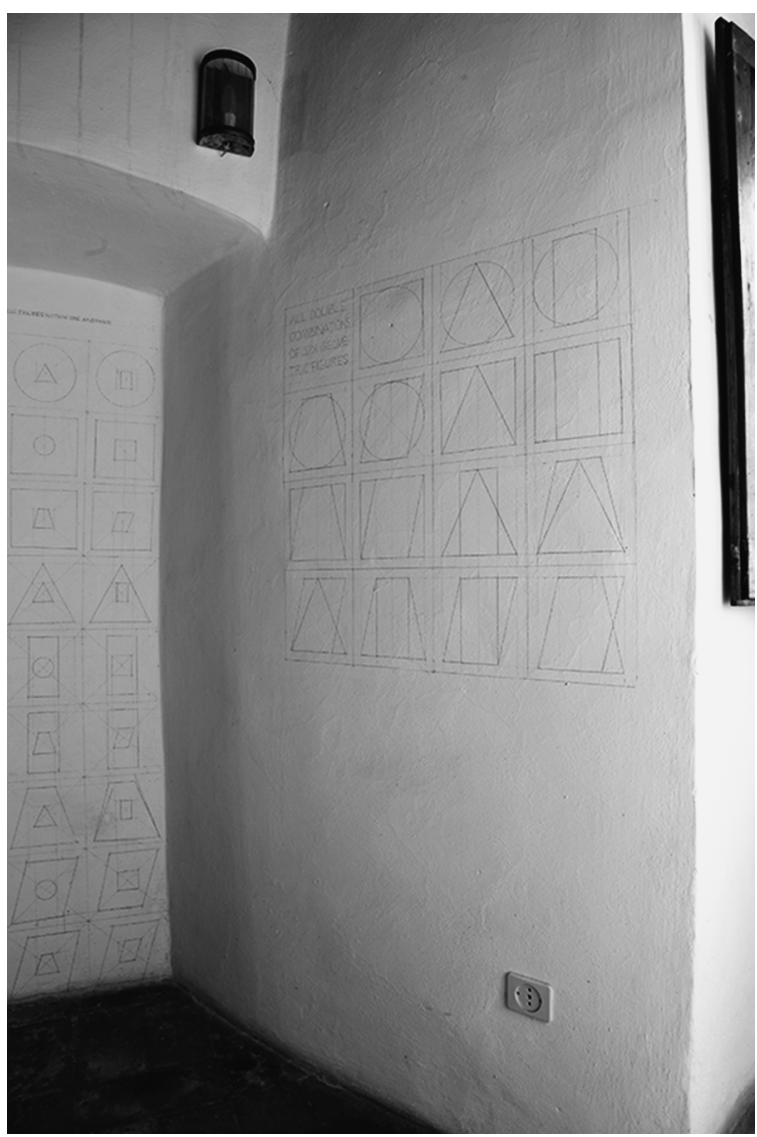

LeWitt. Studio Drawings. 1976. ric figures in the three grid drawings took several tries.

An ostensibly simple problem found no ready solution, and the orderly aspects of LeWitt's drawings are belied by the many mistakes and erasures he made when trying to execute them. The grid drawings thus act as a rejoinder to those who would see LeWitt's geometric work as mathematically or aesthetically pure. The process of making is too messy, too filled with errors, and too playful, the basic shapes closer to children's building blocks than they are to geometric essences, even if these are also evoked. Likewise, the lines, shapes, and words 


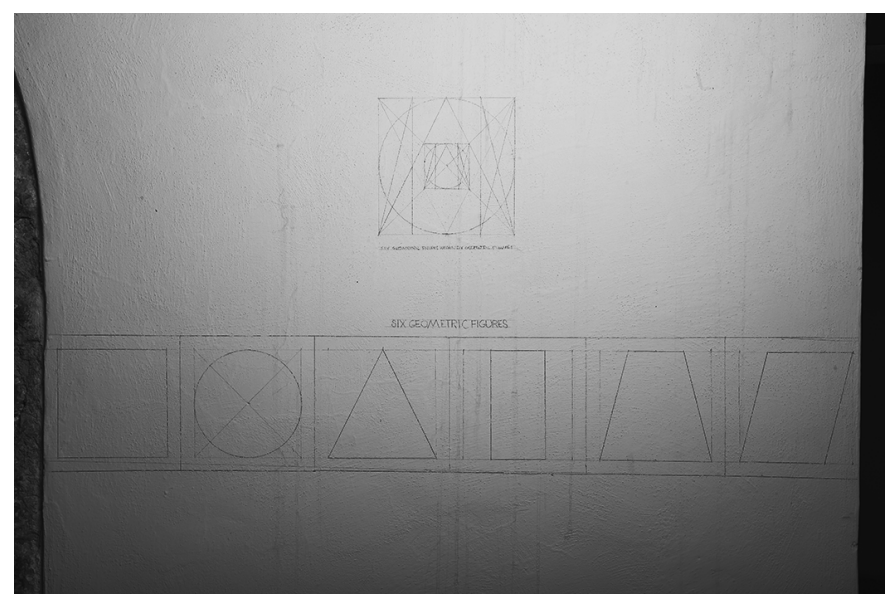

that cover the walls on the other side of the room, which lie somewhere between an elaborate game of connect the dots and a cosmic chart, were often rubbed out and reworked. There are variations in the style, quality, and speed of LeWitt's handwriting, as well as several spelling mistakes. At times, it appears as if the artist had become frustrated, bored, or exhausted by the task he had set himself, on the verge of giving up, even of going out of his mind. In a textual description of a parallelogram, for instance, some of the letters were written back to front with what was probably the artist's left hand. ${ }^{3}$ Up close, they look almost mangled.

The experience of such chaotic details is magnified and redoubled when you try to navigate this group of drawings in its entirety. Large expanses of the room's

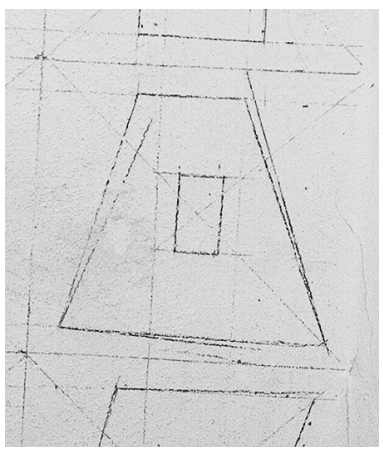
white walls are covered with lines and geometric figures that are connected to other lines, shapes, or architectural points in the room, each of which is paired with a textual description of itself and its precise location. The processes set in motion by the drawings have no beginning and no end, and the experience of navigating them is disorienting and claustrophobic, like getting lost inside a labyrinth. This sense of disorientation is accentuated by the way in which the studio drawings invoke the artist's body in space as a kind of phantasmatic presence, and by the almost uncanny sense that your movements repeat those once made by him. That the lines in the drawings are both embodied and determined-LeWitt's movements were decided by the architecture of the room, the spectator's by the lines, shapes, and words on the walls-is perhaps most keenly felt near the fireplace, where a line connects the base of a wall to an electri-

3. Thanks to Eva LeWitt for informing me that Sol LeWitt was right-handed. 


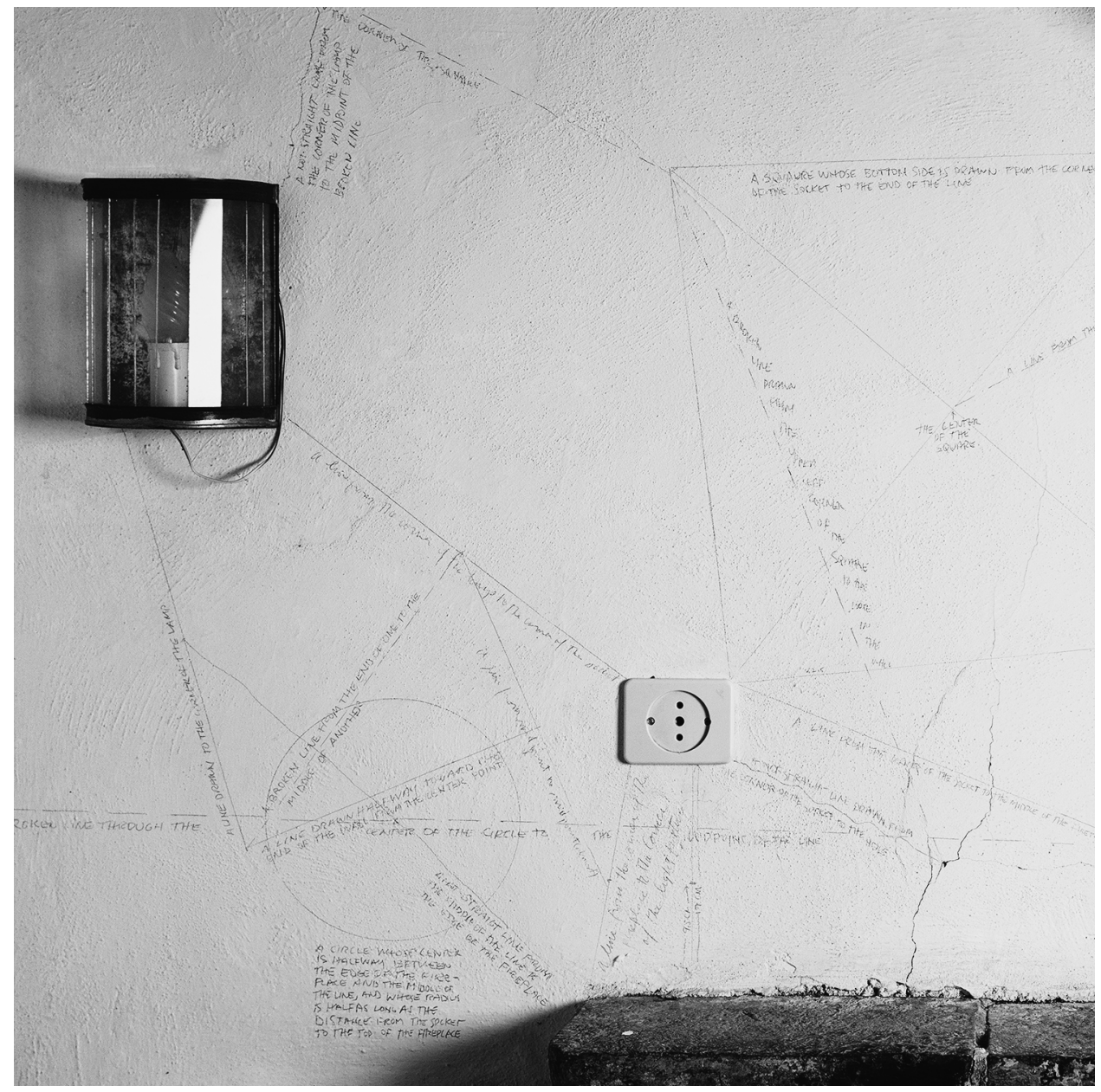

Left and above: LeWitt. Studio Drawings. 1976. 
LeWitt. Studio Drawings. 1976.

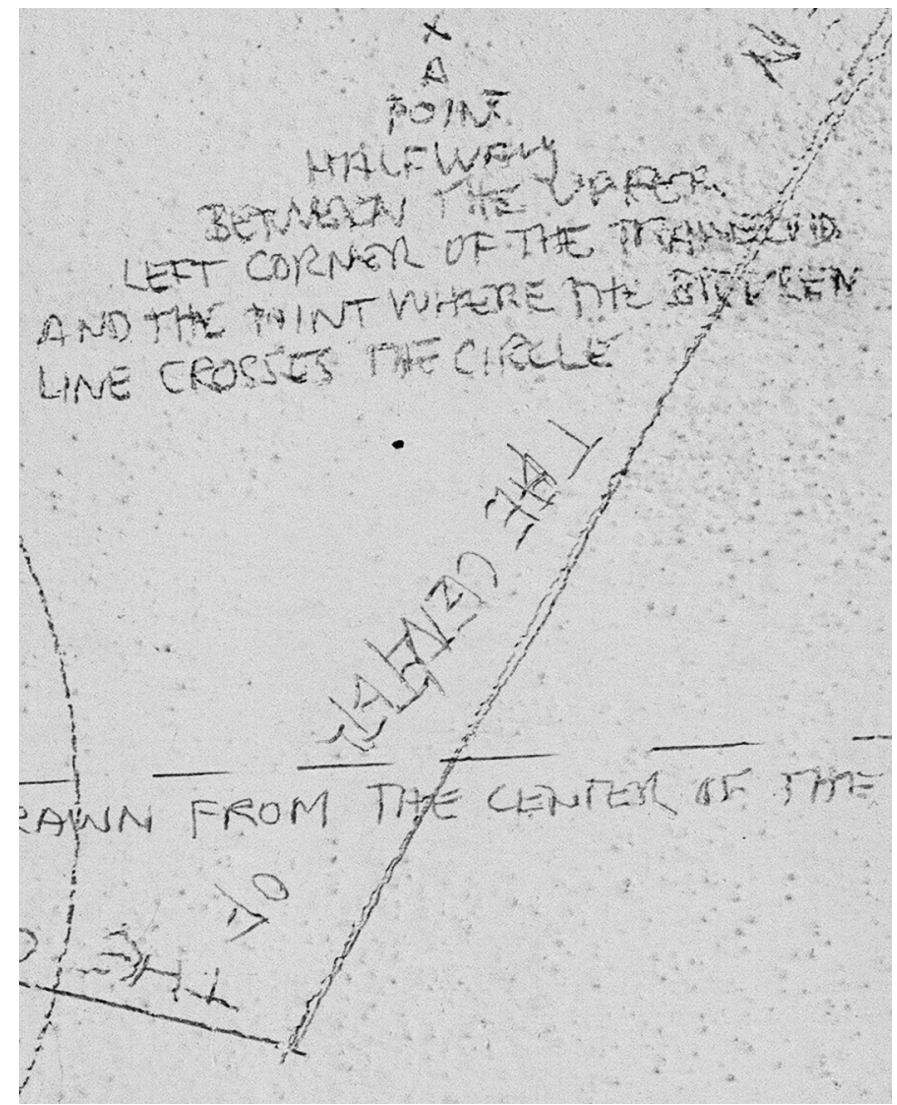

cal socket. In order to draw it, LeWitt must have stood in an alcove and bent down uncomfortably or lain on the ground. The description of this line, also written upside down, reads: A NOT-STRAIGHT LINE DRAWN FROM THE LOWER RIGHT CORNER OF THE WALL TO A POINT HALFWAY BETWEEN THE RIGHT EDGE OF THE WALL AND THE RIGHT SIDE OF THE SOCKET.

The vision of the artist alone in a tower combining shapes and joining dots is absurd. How, one might ask, did art-making come to this? Yet the drawings operate in different registers at once, and their absurdity does not prevent the experience of walking into LeWitt's former studio, austere and evenly lit by a flat, gray light, from being both intimate and intrusive, like entering the scene of a private struggle. The process of drawing has transformed the physical space of the studio into a psychic and corporeal space, both involuted and solipsistic. This sense of interiority is further complicated and made ambiguous by the use of constraints, which makes it difficult to locate the agency in the drawings, or to come to terms with the form of subjectivity at stake. The result of combining six geometric figures 
inside three grids is predetermined by the idea- "a machine that makes the art," 4 in LeWitt's formulation-and the traces of the artist's subjectivity are only residual, the remains of a procedure that are most pronounced when the mechanism breaks down, in mistakes or erasures. The same can be said for the other group of studio drawings, where the use of the room's architecture as a constraint undermines the notion that it was the artist who decided the direction of each line. Instead, almost every architectural point in the room-the edge of a wooden beam, for example, or the corner of a socket-generates lines, shapes, and words that are implicated in the generation of further lines, shapes, and words in a process that is potentially infinite. ${ }^{5}$ Even the positions of hypothetical lines form part of the drawings, their descriptions written in the conditional tense ("A LINE THAT WOULD CROSS ..."). That a hole in a wall could be generative emphasizes the

4. Sol LeWitt, "Paragraphs on Conceptual Art," Artforum (June 1967), p.80.

5. Thanks to Juliette Kennedy for her informative comments about art and infinity.

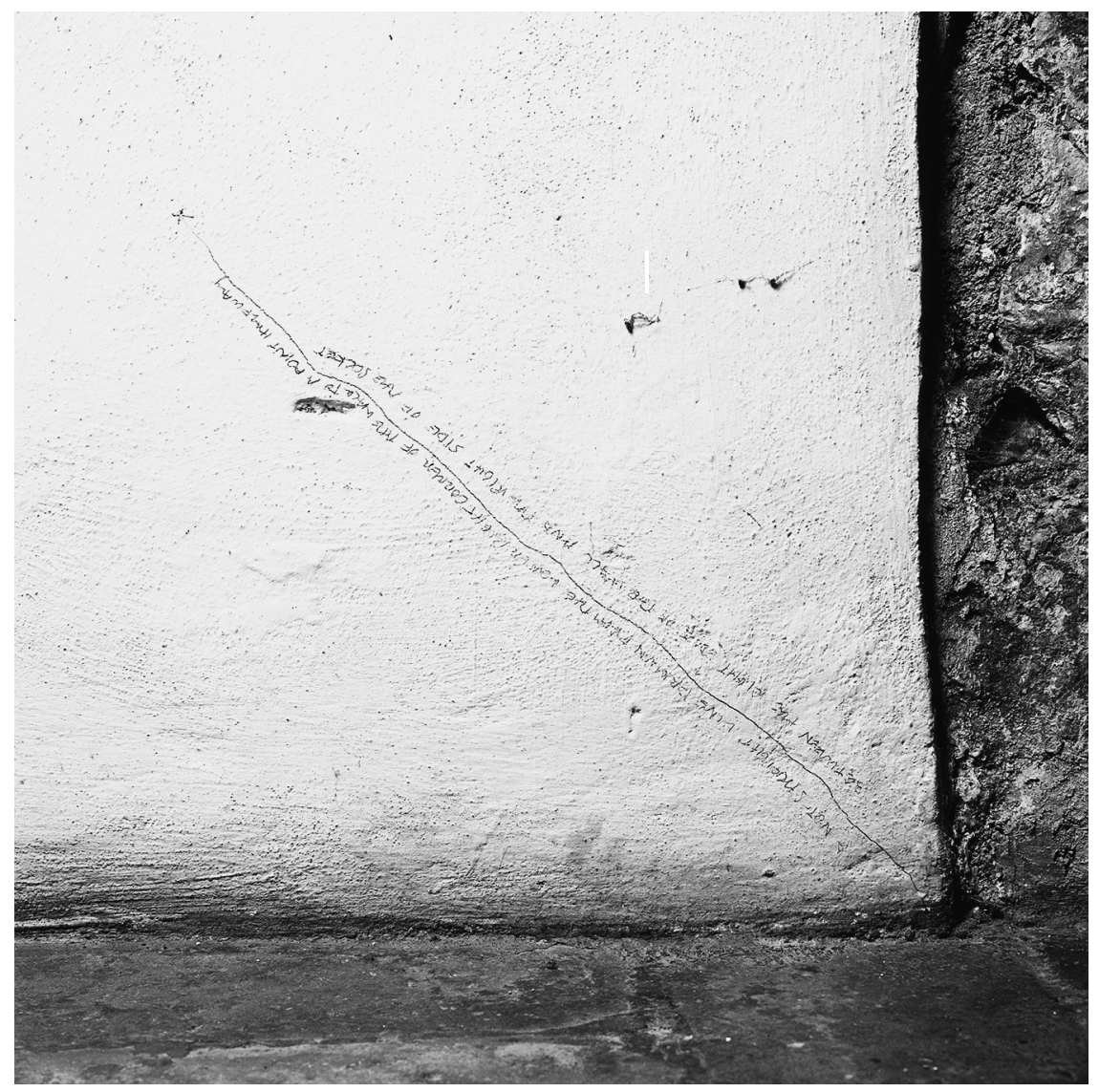

LeWitt. Studio Drawings. 1976. 
degree to which chance elements determine the direction of LeWitt's lines, while also lending the studio drawings a performative character. The provisional and aleatory quality of the drawings invokes a mode of visual production-in-performance, as if the actions of the artist's body were being choreographed by a notational system whose rules were submitted to as they were made. It is a system, moreover, that is traversed by a compulsive and irrational movement-what, after all, is rational about making art by connecting every dot in a room? The image these drawings call to mind is not that of an artist in an ivory tower, but of a madman in his cell, of a body compelled to stretch, crouch, and strain according to the demands of the line, lost inside a labyrinth of its own making. In a 2003 interview, LeWitt said that by the time of his move to Italy in 1976, the same year the studio drawings were made, he had become a "prisoner" 6 of his own ideas and statements. Imprisonment seems an adequate way of describing what it might have felt like to make these drawings, and it does much to express what it feels like to spend time with them.

That the use of constraints might lead to a sense of exhaustion and confinement was already latent in the principles set out in the artist's writings published a few years previously. For LeWitt, Conceptual art was an ethical project as much as it was an aesthetic one. The privileging of the idea released art into a space where it could fulfil its inherent connections, while the artist's will and ego were held in check by preestablished rules. This mode of artistic production worked against the expressive and gestural spontaneity that had dominated the New York art scene until the late 1950s in the paintings of the Abstract Expressionists, and undermined the related ideology of art as self-expression. In order to minimize the role of subjectivity in the process of making, the ethical imperative was to follow the idea to its furthest reach, even if this led to chaos or what LeWitt described as the idea's "ruin." It was for this reason that the Conceptual artist could be described as a "mystic," a figure who worked intuitively as a kind of conduit through which the idea or rule found its expression, as in a form of automatic drawing or writing. This was also why it did not matter if the work was made by an assistant. Whatever differences might emerge, either through error or because of differences in draftsmanship, would form a necessary part of the final work.

Yet this ethic of depersonalization also carried the potential to run amok, and the processes set in motion could turn themselves inside out in the fulfilment of their own logic. For example, in an earlier wall drawing called Wall Drawing 51 (All architectural points connected by straight lines [blue snap lines]) (1970), assistants were instructed to delineate "every possible connection between [the] corner of light-switch plates, elevators, door frames, and walls" 9

6. See Saul Ostrow, "Sol LeWitt by Saul Ostrow," Bomb 85 (Fall 2003), pp. 22-29.

7. Sol LeWitt, "Paragraphs on Conceptual Art," Artforum (June 1967), p. 79.

8. Sol LeWitt, "Sentences on Conceptual Art," Art-Language 1 (1969), p. 10.

9. Sol LeWitt, cited in Sol LeWitt: A Retrospective, ed. Gary Garrels (San Francisco: San Francisco Museum of Modern Art, 2000), p. 43. 


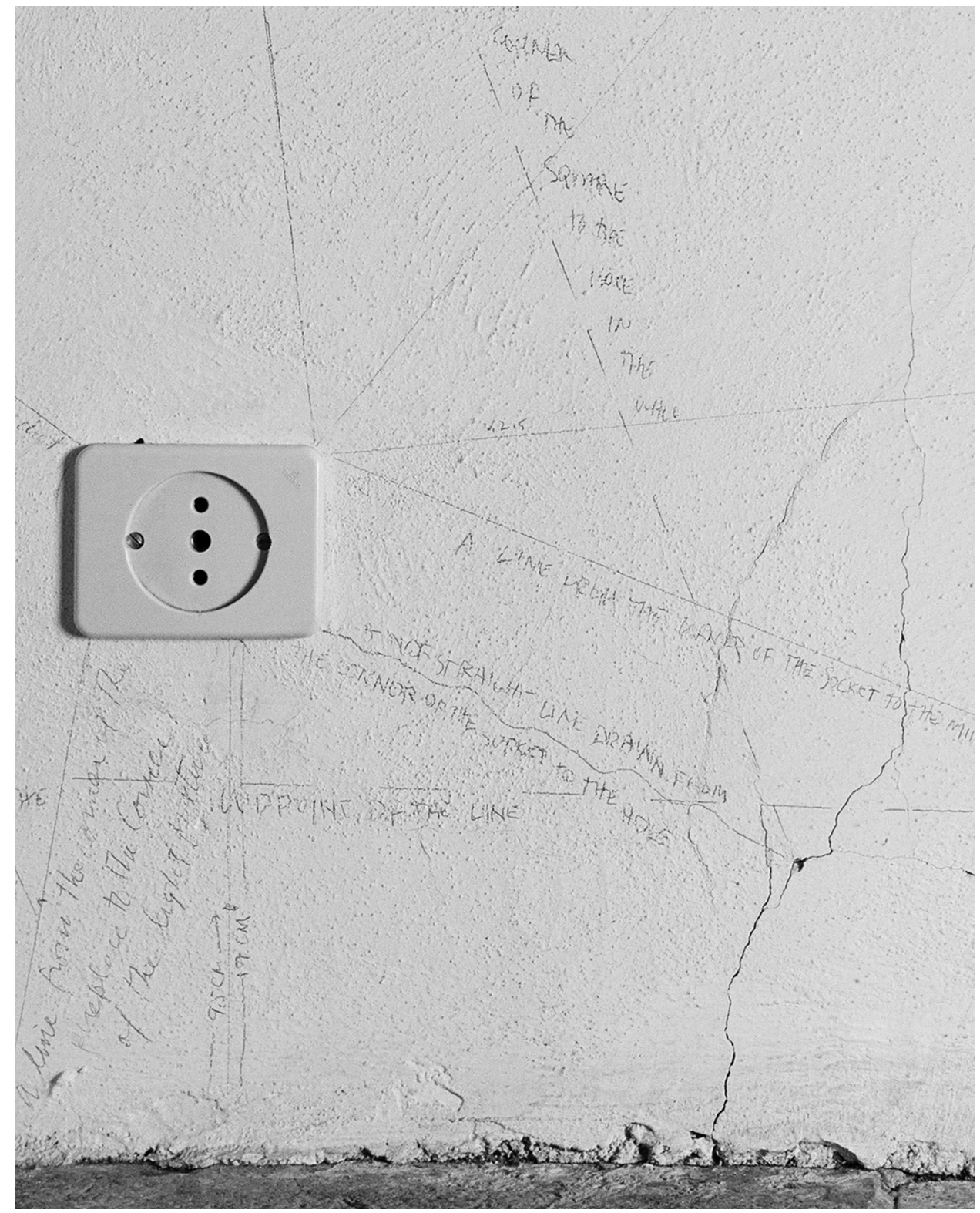

LeWitt. Studio Drawings. 1976. 
with blue snap lines, the kind still used today in design and construction work. As with the studio drawings in the Torre Bonomo, the resulting diagram reads as an intricate map that charts nothing except the intervals between things. The use of a preexisting architectural space as both a support and constraint worked to limit the role of decision-making in the productive process, while the making of each line with a single snap of chalk-coated string reduced gestural expression to a minimum. This form of art-making might also be seen to undo the highmodernist notions of aesthetic autonomy and purity put forward at the time by Clement Greenberg, because the wall drawing's appearance is almost entirely dependent upon the architectural space in which it is made, turning the boundary between the work and the world both porous and highly contingent. But this use of architecture also precluded a subject position whose scope was not predetermined by the idea, leaving the Conceptual artist "at the mercy of the architect," 10 as LeWitt put it in an essay published in Arts Magazine in 1970. In brief, if the strictures of architecture could liberate art from the subjective and expressive, they could also lead to an experience of entrapment. This suggests that Conceptual art was always a contradictory enterprise, at once spiritual and material, free from the illusion of intentionality yet deterministic.

The critical imagination has tended to focus on the ethical dimension of constraints and the ways in which their use resists conventional notions of authorship and expressivity. The same is said for the employment of repetition and seriality, which has also been described, more critically, as an aestheticization of administrative forms of labor in late capitalism, to the point of having "purged all imaginary and bodily experience," 11 as Benjamin Buchloh put it. The studio drawings invite a more complex and contradictory understanding of the place of the subject in Conceptual art, or at least in the idiosyncratic version of Conceptual art that LeWitt advocated. For it would be inadequate to say that the drawings are an expression of the artist's personal mental history. If they suggest that by 1976 LeWitt had become entangled in his own neurotic net, left at the "mercy" of that phantasmatic, almost theological entity the artist refers to as "the architect," then this is because whoever enters his former studio is compelled to do so in turn, to follow the lines laid down on the walls and to experience a similar drive towards an endless, degrading repetition. One might also say that solipsism and neurosis are the forms of subjectivity, or perhaps the forms of pathology, brought into being by the body, the drawings, and their relationship to architectural space. Such a reversal was arguably implicit in a portrait Mel Bochner made of the artist in 1968 titled Closure: Portrait of Sol LeWitt, which forms part of a series he made of friends such as LeWitt, Eva Hesse, and Robert Smithson. In Closure, synonyms for

10. Sol LeWitt, "Plan for Wall Drawing, Paula Cooper Gallery, New York, 1969," first published in July 1969 (New York: Art Press, 1969); reprinted in Sol LeWitt, ed. Alicia Legg (New York: Museum of Modern Art, 1978), p. 93.

11. Benjamin H. D. Buchloh, "Conceptual Art (1962-1969): From the Aesthetic of Administration to the Critique of Institutions," October 55 (Winter 1990), p. 143. 


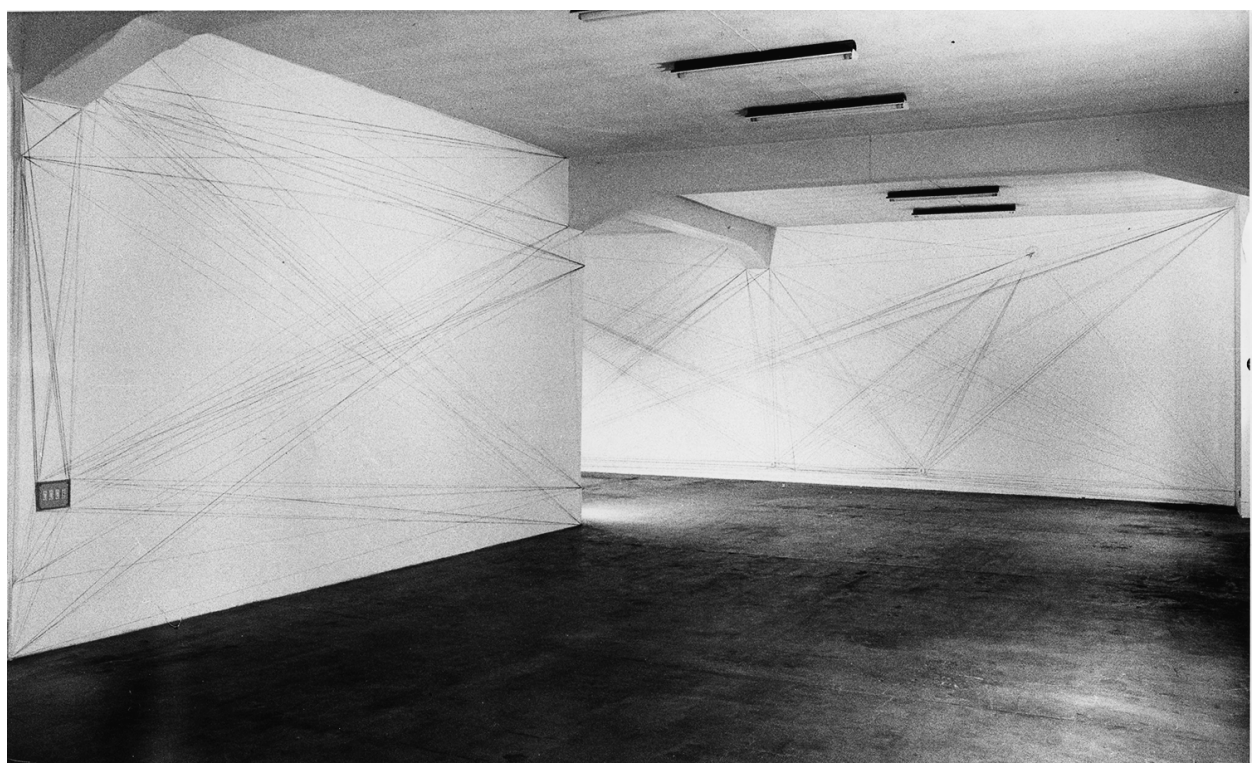

LeWitt. Wall Drawing 51 (All architectural points connected by straight lines [blue snap lines]). 1970.

the word "closure" such as "congested" and "choked" were drawn from Roget's Thesaurus and written in block capital letters on a small, square piece of grid paper. The repetition of words in the work invokes a sense of solipsism and compulsion, while the final comma indicates that the synonyms might proliferate endlessly, even if the list is contained and bounded by the geometry of the square. As Fer has observed, it would be a mistake to see Bochner's thesaurus portraits as entry points into the psyche of the named artists. Instead, they are portraits of their works and what these works do. One might talk, for example, of a LeWitt effect, or a Hesse effect. ${ }^{12}$

Indeed, the studio drawings are not the only instance in LeWitt's work where the relationship between mapping and subjectivity was explored and put into question, and it is suggestive that in each case a similar disruptive impulse is encountered. To take one example, four years after producing the studio drawings, LeWitt made a book called Autobiography (1980). To produce the work, the artist photographed every item in his New York studio-coats, maps, plugs, tapes, and tools all form part of the book-and placed the black-and-white images in a three-by-three grid. The resulting book barely fulfils the minimal conditions of its genre. Except perhaps for an obsessive desire to document and record, Autobiography reveals nothing about LeWitt's personal feelings or outlook, and the

12. For a discussion of this series of works and of lists more broadly, see Briony Fer, The Infinite Line: Re-Making Art After Modernism (New Haven: Yale University Press, 2004), pp. 155-56. 


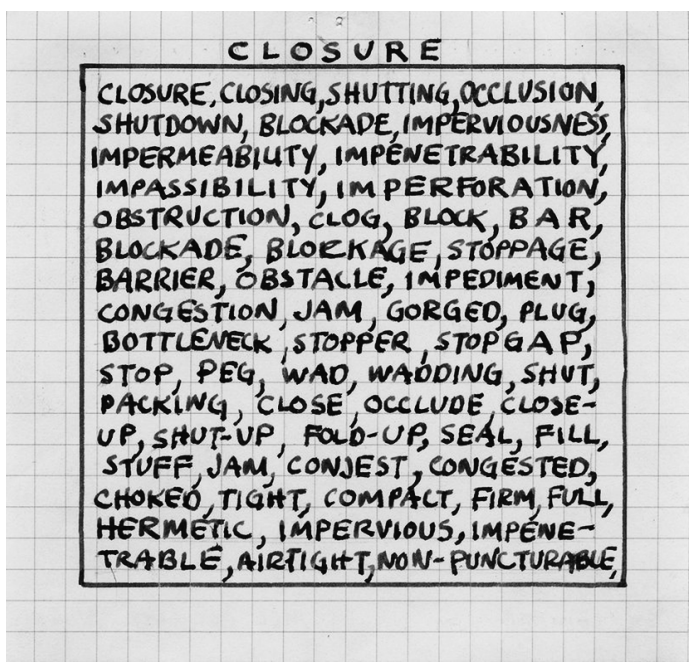

Mel Bochner. Closure:

Portrait of Sol LeWitt. 1968. only image one might expect to find in the book, an image of the artist himself, is absent-except, absurdly, for the top of his bald head. LeWitt once described the Conceptual artist as a "clerk cataloguing the result of the premise."13 Correspondingly, Autobiography reads as a kind of visual inventory in which the space of the studio is reordered according to strict taxonomies, with each set of objects grouped according to type. Yet to argue that the book simply mimics the aesthetics of administration would overlook the sheer absurdity of the undertaking, as though a whole life could be reduced to so many fixed items that only needed adding up and balancing. It would also fail to account for the phantasmagorical quality of the images in the book. Meanwhile, if the grid provides LeWitt with a classificatory system, the studio drawings alert us to the workings of a more disorienting logic. If Autobiography is seen as a kind of map of the studio, with each image marking a point in the given space, then the line connecting the photographs would be twisting and circuitous, a kind of scribble or labyrinth. The image of the rebus or puzzle also comes to mind: It is as if the internal topology of the studio had been "cut up not only into inert, formless elements containing little information or signifying power, but also into misleading elements, carriers of false information," 14 to borrow Georges Perec's description of puzzle-making in his semi-autobiographical novel Life: A User's Manual (1978). This may partly account for the psychic and affective charge of the images in the book, which can have little to do with the objects represented-a plug, say, or a shoe.

Rather than eclipse subjectivity tout court, then, it would be more accurate to say that LeWitt's work reconfigured what the subject of Conceptual art might look like. The "auto" in Autobiography has more to do with psychic and corporeal automatism than it does with what conventionally goes under the name of the self, the artist's body progressing by means of displacement from object to object and

13. Sol LeWitt, "Serial Project No. 1 (ABCD)," Aspen 5-6 (Fall-Winter 1967), n.p.

14. Georges Perec, Life: A User's Manual, trans. David Bellos (Vintage: London, 2003), p. 191 (translation modified). 
not according to any psychological motivation. The same might be said for From Monteluco to Spoleto (1977), a lesser-known book LeWitt made during the period he was using the Torre Bonomo as a studio. The images in the work, which include paths and walls, were placed in a grid identical to the one found in Autobiography. They document various stages of LeWitt's journey as he walked from the Bonomo's hermitage in the mountains to the tower, and each photograph might be seen to mark a pause in the artist's passage, a point on a map. Yet the book's title is deceptive. It suggests that the artist's journey was linear, or at least that the photographs in the book are organized sequentially. But the result is dislocating and disorienting. Here, too, there is a disjunction between the map and the territory it describes: The line connecting each point would be twisting and circuitous,

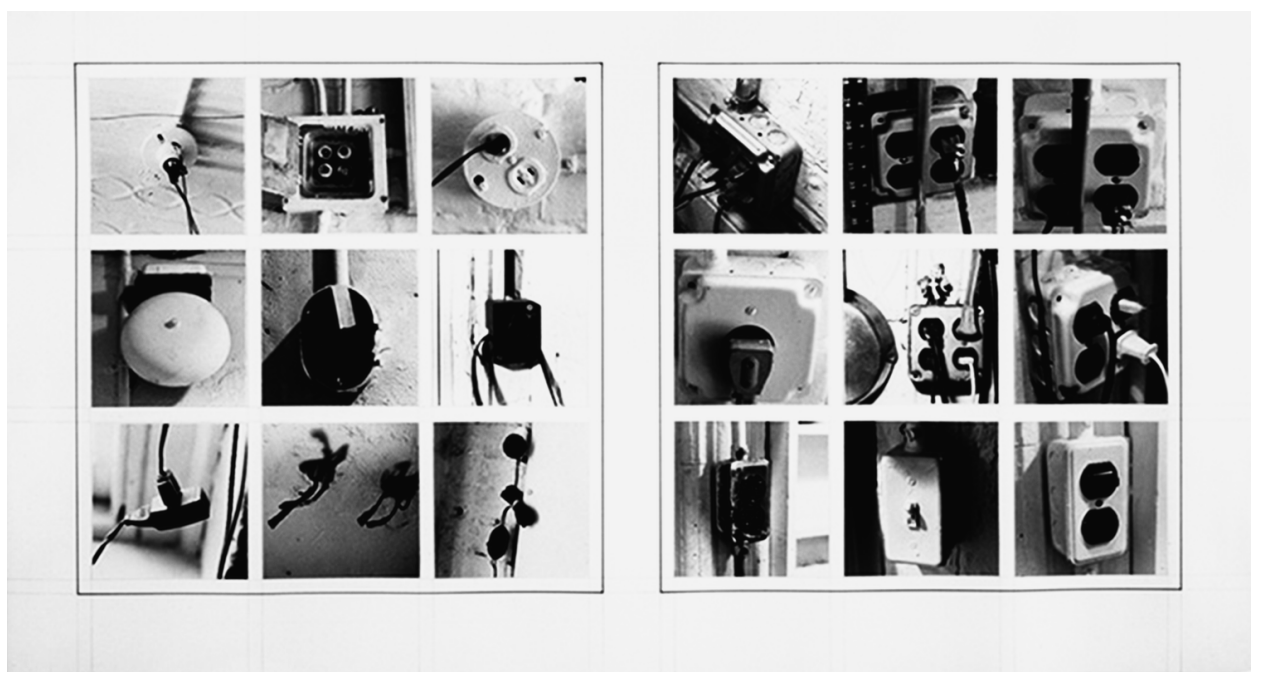

LeWitt. Autobiography. 1980.

a labyrinthine path filled with turnings, divergences, and detours.

The studio drawings in the Torre Bonomo dramatize and exacerbate these operations, giving way to an experience of confusion and a more pronounced material excess. This can partly be accounted for by the fact that they were made by hand, which opens them to accident, and by LeWitt's often maddeningly meticulous textual descriptions, in which precision leads not to conceptual clarity but to opacity. ${ }^{15}$ Yet, above all, it is because there is no end to this interminable game. In Autobiography, the number of images in the book is limited by the objects that occupy the given space, even if it would be difficult to decide what should or should not be included-if plugs are, then why not cracks in walls? A similar claim

15. David Batchelor has discussed these qualities of LeWitt's work in "Within and Between," in Sol LeWitt: Structures 1962-1993 (Oxford: Museum of Modern Art, 1993). 
could be made for Wall Drawing 51 (All architectural points connected by straight lines [blue snap lines]). If the work is susceptible to almost infinitely varied realizations, its inner logic is finite. However many rooms there are in the world, there are only so many "corners of light-switch plates, elevators, door frames, and walls" that can be joined in any one of them, even as the lines themselves are sometimes difficult, if not impossible, to chart. By contrast, in the studio drawings, the lines, shapes, and words that describe them emanate laterally with potentially infinite effect.

In an essay on LeWitt's Autobiography, Rosalind Krauss argues that it is the grid in the book that provides the structure in which the subject comes into being, lending Autobiography what she calls its "schizoid"16 character. In the Torre Bonomo, it is architecture, or rather that phantasmatic entity LeWitt refers to as "the architect," to whose will the Conceptual artist submits and is left at the "mercy," which drives this expansive but involuted movement from zero to infinity. How might the split, schizoid character of the drawings be accounted for? And what exactly is being mapped or located? To what problem is the solution being sought?

At the beginning of Life: A User's Manual, a novel that is itself structured like a map or puzzle, Perec observes how puzzling is never a solitary game because the puzzle-maker has made every move before: "Every blunder and every insight," he writes, "each hope and each discouragement, have all been designed, calculated, and decided by the other."17 Like LeWitt's "architect," the entity Perec calls a "puzzle-maker" or "other" does not refer to the author himself, but to the schizoid character of play, to the sense that the subject who plays is the content of the other's experience. Likewise, to spend time with the studio drawings is to feel how, like a puzzle, this game is, and never was, a solitary one. The drawings call to mind not only a madman or prisoner but also a child preoccupied with, or absorbed by, drawing or playing. But if the drawings share the character of a child's game, it is not because of their formal simplicity-after all, a scribble can be formally complex, even if it communicates little to the outside world (though this recalcitrance may itself form an unconscious communication). It is because of their split and solipsistic character. The child psychologist Jean Piaget once observed how "the solitary talker invokes imaginary listeners, just as the child invokes imaginary playfellows." 18 Likewise, the studio drawings share the invocatory character of a child's game, as well as that of other internal soliloquies, an entreaty or a prayer, for instance. These last forms of inner speech are employed when a person regressively invokes a wish-fulfilling other. Could LeWitt's "architect" be seen as such an entity? This would begin to make sense of the splitting that takes place in the studio drawings between the personal and the impersonal, the "I" and the "not-I." It

16. Rosalind Krauss, "LeWitt Matrix," in Sol LeWitt: Structures, p.54.

17. Perec, Life: A User's Manual, p.18.

18. Jean Piaget, Language and Thought of the Child, trans. Marjorie and Ruth Gabain (London: Routledge, 2002), p. 2. 
would also help to account for the way in which oppositions such as play and compulsion, chance and necessity, the created and the given, slide into one another. For it is architecture that precedes the drawings, and it is architecture that decides, in the last instance, the direction of each itinerant line.

Among the many books in LeWitt's former home in Monteluco is a volume by the artist, writer, and architecture critic Adrian Stokes, The Stones of Rimini (1969), an exploration of quattrocento art and architecture, subjects LeWitt became interested in upon his arrival in Italy. The extent to which he engaged with Stokes's writings is unknown, though the book might nevertheless be seen as another point in the artist's working environment. Stokes was particularly important because of his interpretations of architecture through the lens of Melanie's Klein's psychoanalytic writings, especially her notion of the part-object. In the third section of his book Smooth and Rough (1951), fittingly called "Houses and Machines," Stokes argued that architecture could be understood as an "ego-defining object" or as "the mother of the arts." 19 For Stokes, architecture had a reparative function, working to alleviate the persecutory and depressive anxiety that resulted from the infant's attacks on the mother, whether real or fantasized, who was symbolized in architecture as a "whole object" that had survived these acts of aggression intact and was therefore able "to hold firm the [infant's] flux of feelings." 20 Buildings, in Stokes's terms, are "giants of ourselves." Carving is synonymous with sadism, modeling with reparation, while walls, with their textures and apertures, their smooth and rough planes, can function as the liminal spaces of an encounter between internal affects and their external translation.

To gender architecture as maternal is perhaps cliché, and Stokes's analogies are sometimes too literal. Nor does his vision of architecture as reparative account for the less benevolent character of the "architect" in LeWitt's work, which also provokes an experience of disorientation and coercion, as well as the sense of an endless search. It might be more germane to imagine architecture, like Perec's "puzzle-maker" or "other," as an ego-defining object or as art's lost object. Such a view also invites a shift of attention away from the prehistory of the individual to that of art-parenthetically, when asked whether he was the first person to draw on walls, LeWitt once quipped that the cavemen were, which makes a similar point. ${ }^{21}$ Nevertheless, with Stokes's metaphorics in mind, it is suggestive that there appears to be an unconscious synonymy in LeWitt's work between drawing and cutting. This was implicit in the two books addressed earlier, Autobiography and From Monteluco to Spoleto, where, as in a puzzle, the topology of the given space was cut up and reorganized into a superficially ordered system. Yet it was made more explicit in a series of map works the artist referred to as "cuts," which he started

19. Adrian Stokes, "Mother Art," in Art and Analysis: An Adrian Stokes Reader (London: Karnac Books, 2014), p. 80.

20. Ibid., p. 90.

21. Sol LeWitt, cited in Sol LeWitt (Kunstverlag, AG: JRP Ringier), p. 255. 

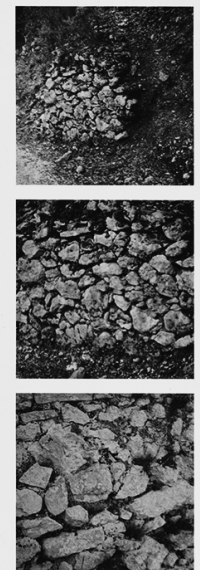
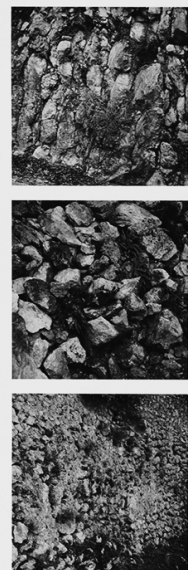
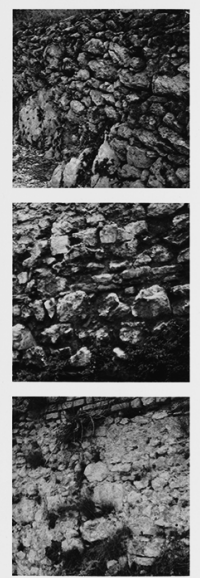
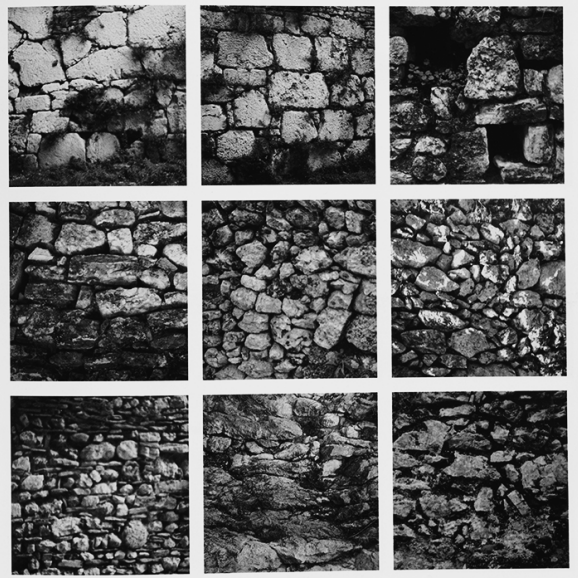

LeWitt. From Monteluco to Spoleto. 1976.

making in 1976, the same year as the studio drawings. To produce these works, the artist incised spaces or geometric shapes out of commercial maps. In some this small act of violence appears arbitrary, though it is noteworthy that the holes sometimes echo the shapes found on the walls of the Torre Bonomo. In other works, the shape of the incision was determined by LeWitt's movements in a particular city. The full titles of these last works, which take the form of inventories or lists, can be dizzyingly long, as in Map of Florence with the Area Between Piazza San Marco, via Cavour, via Guelfa, via de Ginori, Borgo S. Lorenzo, via Roma, via d'Posinghi, via Calsamoli, via Speziali, Piazza Della Republica, via Calimala, via Por S. Maria, Piazza de Pesce, Lungarno Archibuse, Lungarno Generale Diaz, via del Benci, via Ghibelluca, via del Proconsolo, Piazza Duomo, via del Servi, Piazza delle SS. Annunziata, via C. Battisti, and via Ricasoli Removed (1976), where the artist plotted the various routes he took while walking around Florence, cutting out the resulting geometric shape. Like the list of memories in Perec's I Remember (1978) — which includes everything from an exhibition by Yves Klein to the diagram that serves as this essay's epigraph, a line that traces the novelist's labyrinthine journey on the metro in Paris and which also has the virtue of becoming tangled into a grid-LeWitt's "cuts" are objective and impersonal in character, revealing nothing about his inner world. Meanwhile, if the process of making is both subtractive and involuted, contracting inwardly in scale-a street determines the direction of the line that is walked, which, in turn, determines the line that is drawn, which, finally, determines the line that is cutin the imagination these holes can expand dramatically, regardless of their actual size. To take another example, Map of London with Area between Euston Road, Tottenham Court Road, Charing Cross Road, Shaftesbury Avenue, Piccadilly Circus, Regent Street, Pall Mall, St James's Street, Piccadilly, Berkeley Street, Burton Street, New Bond Street, 
LeWitt. A Square of Chicago Without a Circle and Triangle. 1979.

LeWitt. Map of Florence with the Area

Between Piazza San Marco, via Cavour, via Guelfa, via de Ginori, Borgo S. Lorenzo, via

Roma, via d' Posinghi, via Calsamoli, via

Speziali, Piazza Della Republica, via

Calimala, via Por S. Maria, Piazza de Pesce,

Lungarno Archibuse, Lungarno Generale

Diaz, via del Benci, via Ghibelluca, via del

Proconsolo, Piazza Duomo, via del Servi,

Piazza delle SS. Annunziata, via C. Battisti, and via Ricasoli Removed. 1976.

LeWitt. Map of London with Area between Euston Road, Tottenham Court Road, Charing Cross Road, Shaftesbury Avenue, Piccadilly Circus, Regent Street, Pall Mall, St James's Street, Piccadilly, Berkeley

Street, Burton Street, New Bond Street, Oxford Street, Regent Street Again, Portland Place, \& Park Crescent Removed. 1977.
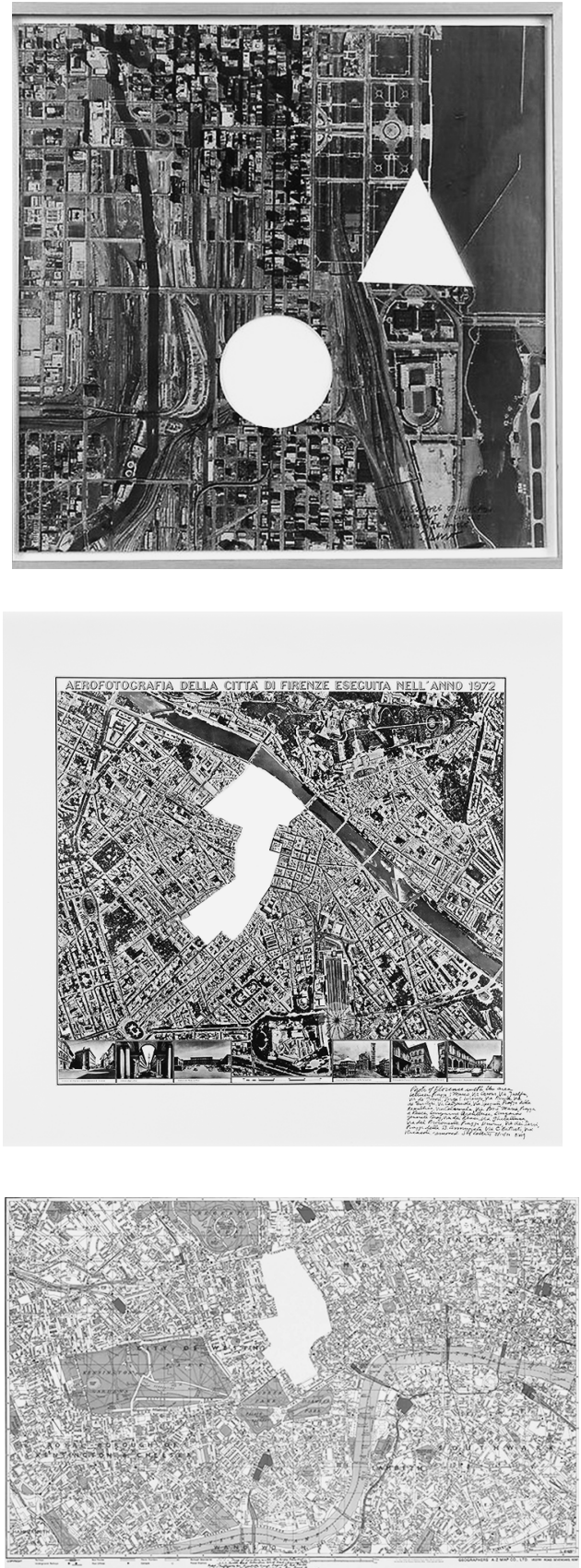
Oxford Street, Regent Street Again, Portland Place, Ev Park Crescent Removed (1977) is obsessively precise and claustrophobic. Yet the line connecting each point is also convoluted and aleatory, the points on the map potentially endless-like a list, they could always be added to-the cut infinitely large.

The unconscious synonymy between drawing and cutting in LeWitt's work, together with the fantasy of architecture as an ego-defining object-one might speak of Conceptual art's architectural unconscious-may help to account for the psychic and affective charge of the studio drawings. It is as if the interior of the studio had been cut up into part-objects, or, conversely, as if the internal space of the studio functioned as a restorative space or holding environment in which lines, shapes, and words were sutured together to form an always elusive whole. On this view, it is suggestive that, in conversation, the gallerist Valentina Bonomo, the Torre Bonomo's owner, intuitively described the studio drawings as "net drawings"-because nets, like grids, are made up mostly of holes, even as they ensnare or help hold things together. A similar claim could be made for both the function of the grid and the puzzling that takes place in Autobiography and From Monteluco to Spoleto, where there sometimes appears to be an equivalence between inanimate objects and body parts, and it is perhaps not

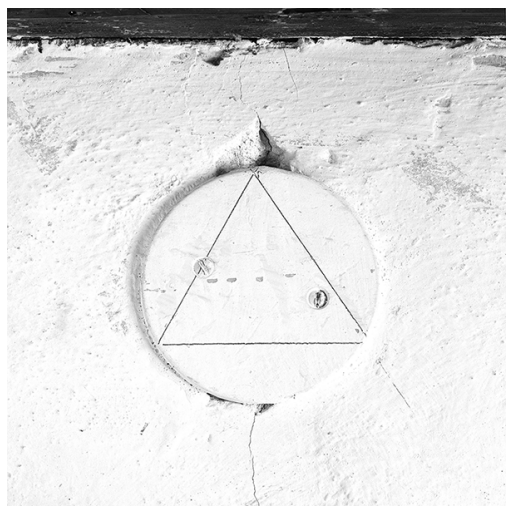

LeWitt. Studio Drawings. 1976. by chance that puzzles, where a whole is cut into parts only to be restored again, were once called dissections. This would help to account for the phantasmagorical and uncanny quality of the images in the books. When seen from this perspective, the studio drawings in the Torre Bonomo might be said to re-stage art's primal scene, dramatizing the coming into being of the subject as well as the schizoid origins of drawing. This may also account for the drawings' anachronistic character: If the drawings make the interior anatomy of the tower visible (architecture after drawing), architecture is the drawings' condition of possibility (drawing after architecture). Such a view is only rein-

forced by the irregular, cracked surfaces of the plastered walls and various damp stains, which lend the walls a corporeal quality, and by the way in which the lines, shapes, and words sometimes seem as intricate and livid as blood vessels. It is as if drawing were an automatic nervous process. In this way, the external surface of the walls becomes, in another register and according to another, less conscious mode of experience, an interior surface, one that transforms the subject into the content of the room's form. Lastly, if it can be said that the studio drawings exist in the shadow of the object, then it is also arguable that every experience of discovery in 


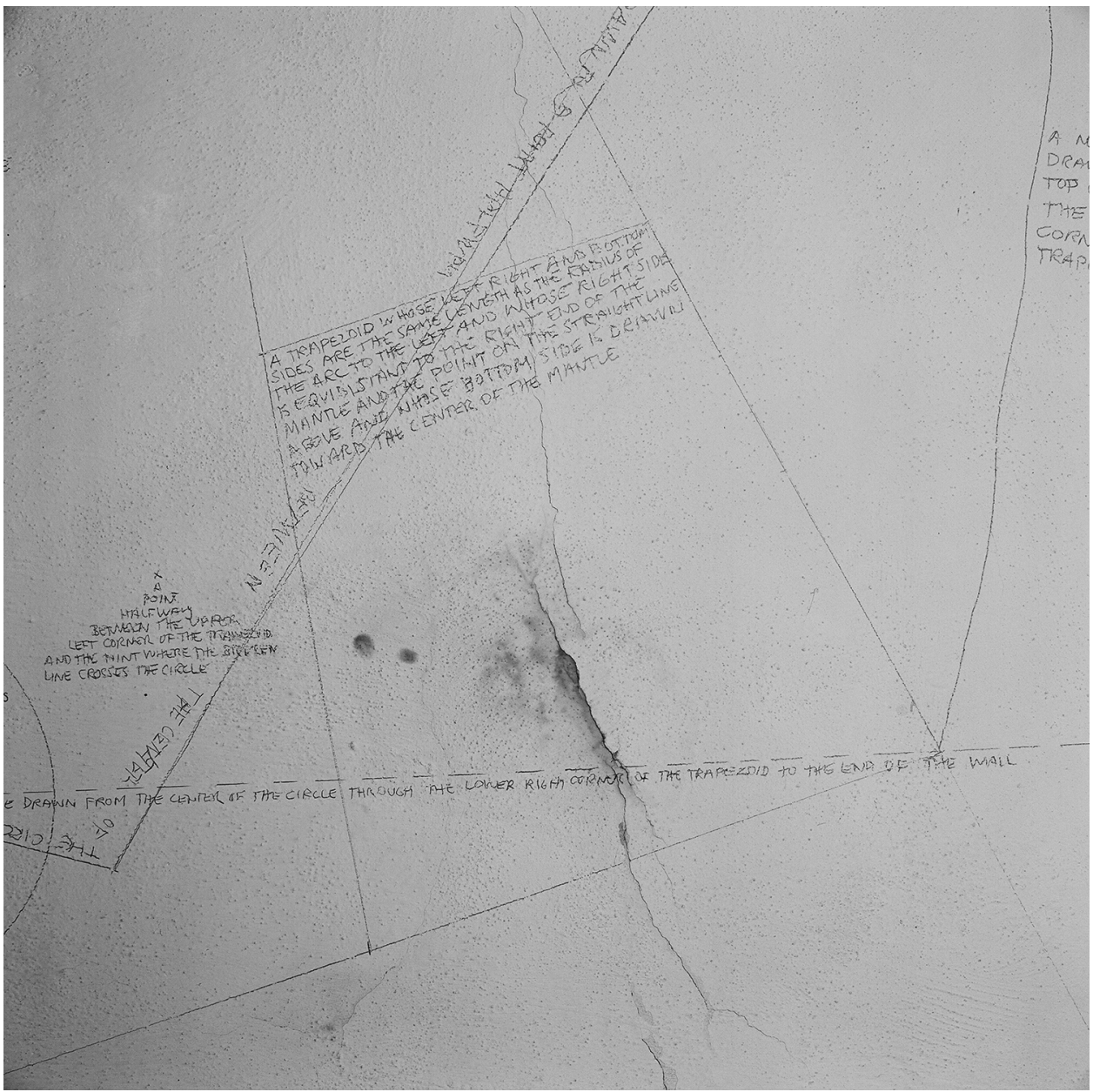

LeWitt. Studio Drawings. 1976.

the Torre Bonomo is but an unconscious repetition of a previous loss, every line the sign of a cut or a scar on the map. Perhaps that is why these "I remembers" invoke a "small, impalpable nostalgia," 22 to borrow Perec's description of the list of memories collected in I Remember.

There is another, little-known work that might help to make sense of the contradictory aspects of the autobiographical impulse in LeWitt's work, and indeed to dramatize the scale of the mapping that takes place in what could, after

22. Georges Perec, Je me souviens (Hachette: Evreux, 1988), n.p. My translation. 


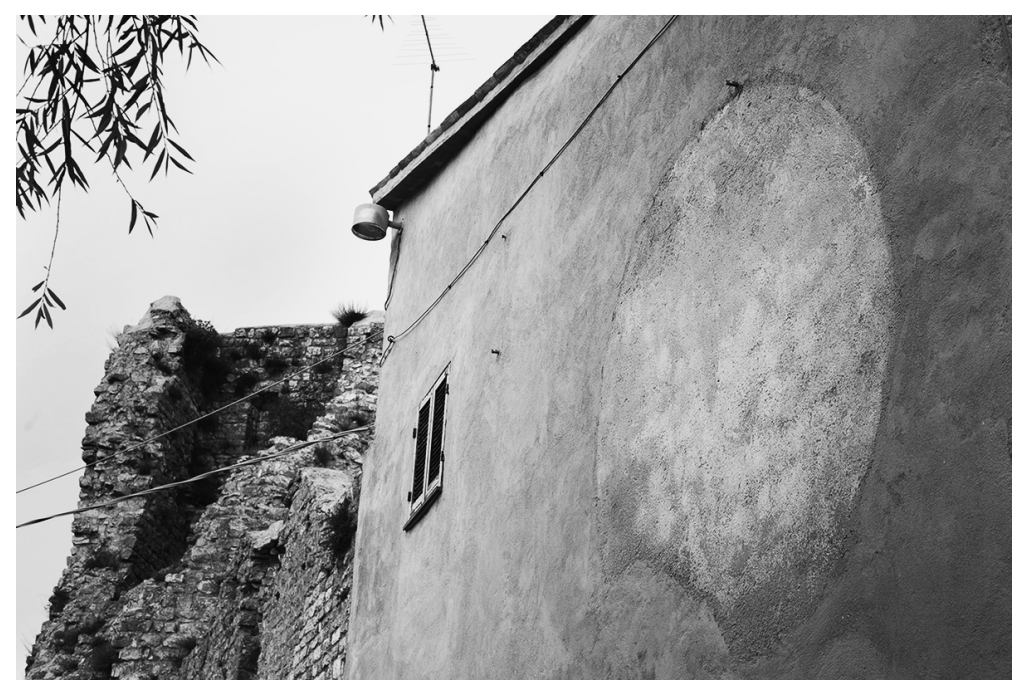

LeWitt. Wall Drawing \#355 (A white circle 80" $(200 \mathrm{~cm})$ in diameter filled in solid). 1981.

Roland Barthes, be called his "lifework" (for Barthes, this notion was premised on an ethical reversal, which he finds in Marcel Proust, where it is not a question of the work looking like the artist but of the artist looking like the work). ${ }^{23}$ In 1981, LeWitt produced a work called Wall Drawing \#355 (A white circle 80" (200cm) in diameter filled in solid), a large, now crumbling white circle on the side of a farmhouse in a remote village called Cancelli only a short drive from Spoleto. A nearby plaque provides the work with another title, Sole Bianco, which is how those who live in the village and surrounding area know it. The estate of Sol LeWitt is unsure how this came to pass, and it would be unusual for the artist to provide such symbolic or personal titles to his works. Yet it is noteworthy that the title makes a direct, if homonymic, connection between the artist and the circle-Sol and Solewhich encourages the work to be seen as yet another point on a map or star in a cosmic chart. Indeed, suns were not far from LeWitt's mind. A year previously, in 1980, and around the same time as Autobiography, he made a book called Sunrise and Sunset at Praiano, in which he photographed various sunsets and sunrises and placed the square images in a two-by-two grid. The book marks time through the revolutions of the Sun in space, but, like the clocks in Autobiography, the images are (1978-1979 and 1979-1980), trans. Kate Briggs (New York: Columbia University Press, 2011), p. 207. 

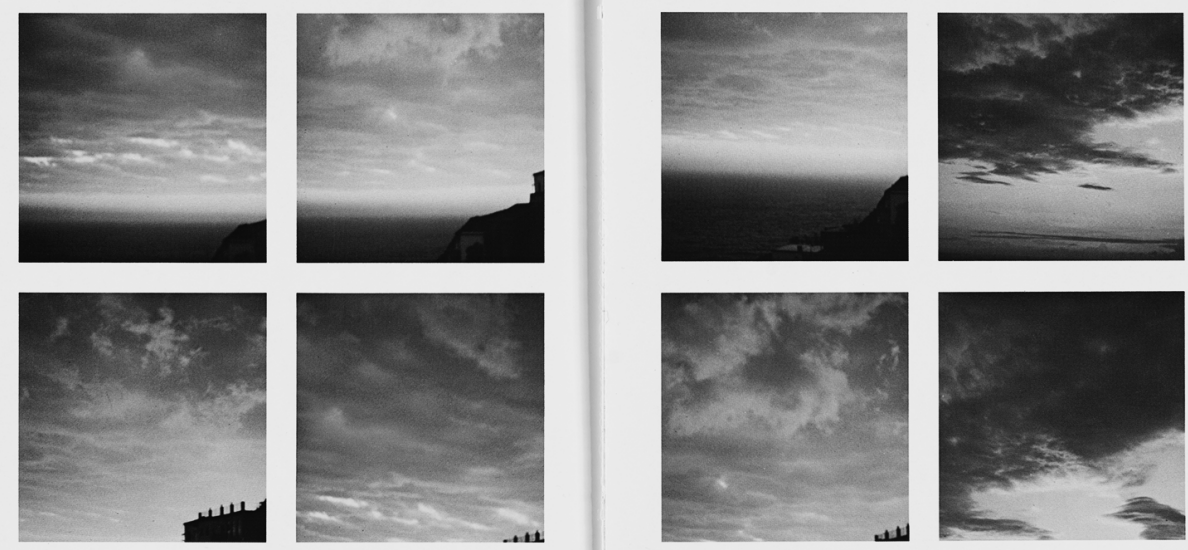

LeWitt. Sunrise and Sunset at Praiano. 1980.

organized anachronistically—sunsets next to sunsets, sunrises next to sunrises-as if the rhythms of the cosmos themselves were susceptible to the dislocating, perhaps entropic, logic of the grid. When seen from this perspective, Sole Bianco's narcissism is pronounced: It is as though each day was its own; as if each morning, its light was shattered into the infinitely variegated colors of the world.

The first time LeWitt drew what he called "not-straight lines" was on the walls of the Yvon Lambert gallery in Paris in 1970, as a tribute to his friend Eva Hesse, who had recently died, and to her work, which inscribed industrial materials in a bodily register. One might say that Hesse survives in LeWitt's work as a detail, a not-straight line among straight lines, hyphenated lines, and hypothetical lines. It would seem that the subject of Conceptual art remains in a similar way, as an enervating memory, something felt here or there: in the twists and turns of a line, an erasure, a spelling mistake, the mess of a letter, or the dust of a white sun. And while it is true that Sole Bianco is not, chronologically speaking, LeWitt's last work-but then it would not really make sense to talk about a last work with LeWitt; like a labyrinth or the studio drawings in the Torre Bonomo, his works go on ending, or go on beginning-there is still a sense in which every line in his work tends infinitely toward it, just as the work tends infinitely toward every other work. Cosmic, perhaps, yet it is a logic that also tips the imagination into an expe- 
rience of claustrophobia and disorientation, the lines filling every corridor of your mind. It is an experience that is thoroughly material and of this world, not transcendental or outside it. Perhaps this is the paradox within which LeWitt's lifework operates. The attempt to find or locate the object on the surface of the physical space occupied, whatever its scale, ends by articulating an absence and in an overarching experience of loss, while the process of mapping does not result in the image of a unified, cohesive subject but in a series of holes, like missing pieces in a jigsaw puzzle. The attempt to map, to make connections between things, appears inseparable from cutting out and disconnecting. This suggests that the desire for order harbors within itself a drive toward disorder. Conceptual art then becomes a matter of measure and unmeasure, of location and dislocation, of rules and unruliness, of making holes where wholes should be. 